\title{
Dengue in Western Uganda: a prospective cohort of children presenting with undifferentiated febrile illness
}

Ross M. Boyce ${ }^{1,2^{*}}$ (D, Matthew Collins ${ }^{3}$, Rabbison Muhindo ${ }^{2}$, Regina Nakakande ${ }^{2}$, Emily J. Ciccone ${ }^{1}$, Samantha Grounds ${ }^{1,4}$, Daniel Espinoza ${ }^{3}$, Yerun Zhu ${ }^{3}$, Michael Matte ${ }^{2}$, Moses Ntaro ${ }^{2}$, Dan Nyehangane ${ }^{2,5}$, Jonathan J. Juliano ${ }^{1}$ and Edgar M. Mulogo ${ }^{2}$

\begin{abstract}
Background: The spatial distribution and burden of dengue in sub-Saharan Africa remains highly uncertain, despite high levels of ecological suitability. The goal of this study was to describe the epidemiology of dengue among a cohort of febrile children presenting to outpatient facilities located in areas of western Uganda with differing levels of urbanicity and malaria transmission intensity.

Methods: Eligible children were first screened for malaria using rapid diagnostic tests. Children with a negative malaria result were tested for dengue using a combination NS1/lgM/lgG rapid test (SD Bioline Dengue Duo). Confirmatory testing by RT-PCR was performed in a subset of participants. Antigen-capture ELISA was performed to estimate seroprevalence.

Results: Only 6 of $1416(0.42 \%)$ children had a positive dengue rapid test, while none of the RT-PCR results were positive. ELISA testing demonstrated reactive lgG antibodies in 28 (2.2\%) participants with the highest prevalence seen at the urban site in Mbarara (19 of 392, 4.9\%, $p<0.001$ ).

Conclusions: Overall, these findings suggest that dengue, while present, is an uncommon cause of non-malarial, pediatric febrile illness in western Uganda. Further investigation into the eocological factors that sustain low-level transmission in urban settings are urgently needed to reduce the risk of epidemics.
\end{abstract}

Keywords: Dengue, Fever, Arbovirus, Epidemiology, Uganda

\section{Background}

Dengue is a mosquito-borne viral disease that is estimated to cause upwards of 400 million infections each year $[1,2]$. While more than half of the world's population is thought to be at risk, the global burden of dengue remains highly uncertain [3]. Nowhere is this epidemiological uncertainty more pronounced than in Africa,

\footnotetext{
* Correspondence: roboyce@med.unc.edu

'Division of Infectious Diseases, University of North Carolina at Chapel Hill, Chapel Hill, North Carolina 27599, USA

${ }^{2}$ Department of Community Health, Faculty of Medicine, Mbarara University of Science \& Technology, Mbarara, Uganda

Full list of author information is available at the end of the article
}

where the requisite laboratory infrastructure to distinguish dengue from other causes of febrile illness is not routinely available $[4,5]$. Despite limited data, there is reasonable consensus for the existence of endemic dengue transmission in many countries, with modeling frameworks suggesting that Africa's disease burden may be similar to that of other high transmission areas, such as the Americas [1].

The East African highlands, including areas of Uganda, Rwanda, and Burundi, represent a region of especially high uncertainly [3]. While previous studies of pediatric admission at sentinel sites across Uganda demonstrated

C C The Author(s). 2020 Open Access This article is licensed under a Creative Commons Attribution 4.0 International License, which permits use, sharing, adaptation, distribution and reproduction in any medium or format, as long as you give appropriate credit to the original author(s) and the source, provide a link to the Creative Commons licence, and indicate if changes were made. The images or other third party material in this article are included in the article's Creative Commons licence, unless indicated otherwise in a credit line to the material. If material is not included in the article's Creative Commons licence and your intended use is not permitted by statutory regulation or exceeds the permitted use, you will need to obtain permission directly from the copyright holder. To view a copy of this licence, visit http://creativecommons.org/licenses/by/4.0/ The Creative Commons Public Domain Dedication waiver (http://creativecommons.org/publicdomain/zero/1.0/) applies to the data made available in this article, unless otherwise stated in a credit line to the data. 
a relatively low prevalence of arboviral infections, these findings are limited by the spatial and temporal trends in sampling. In contrast, the indirect evidence supporting endemic dengue transmission in Uganda is relatively strong. There are favorable precipitation and temperature conditions, the Aedes aegypti mosquito the primary vector of dengue, along with yellow fever and Rift Valley fever - is ubiquitous in Uganda. Dengue outbreaks and transmission have been documented in neighboring countries, and cases have been reported among travelers returning from Uganda $[1,6,7]$. Other factors favoring the likelihood of dengue transmission in Uganda include an increasingly globalized economy and rapid urbanization $[8,9]$.

While the majority of dengue infections result in either asymptomatic or mild, self-limited clinical disease, the potential health system and economic impact of dengue transmission in a malaria-endemic country like Uganda represents an important knowledge gap. Given the nonspecific symptoms and lack of available diagnostic tools, dengue infections may frequently be misdiagnosed and empirically treated as malaria [7]. This likely contributes to (i) over-estimation of malaria transmission, (ii) overuse of artemisinin combination therapies (ACT), perhaps accelerating to the development of resistance, and (iii) inadequate resourcing of dengue surveillance and control measures, which generally do not overlap with malaria control strategies such as insecticide-treated nets (ITN) [10].

Defining the burden of dengue in Uganda is critically important, especially as new tools such as vaccines become more widely available [11]. Therefore, the overarching aim of this study was to describe the epidemiology of dengue among a cohort of children presenting to outpatient public health facilities in western Uganda with acute febrile illness.

\section{Methods}

\section{Study setting}

The study was conducted at two sites in the Kasese District and one site in the Mbarara District of Southwest Uganda (Fig. 1). These facilities were purposefully selected to examine dengue as a potential cause of nonmalarial febrile illness across different ecological settings and in areas of varying malaria transmission intensity [12] (Table 1). While little is known about the seasonality of dengue transmission in Uganda, malaria transmission is characterized by semi-annual transmission peaks typically following the end of the rainy seasons [13]. Therefore, the study was planned to take place over a period of at least 6 months to capture both rainy and dry seasons. There are no government-provided diagnostic tools or standardized treatment protocols for dengue fever at public health facilities in Uganda [14].

\section{Study design}

The study was a prospective, observational cohort design, enrolling children seeking care for febrile illness from November 2017 to June 2018. Children (age $<18$ years) presenting to one of three outpatient clinics with documented fever (axillary temperature $\geq$ $38^{\circ}$ celsius $[\mathrm{C}]$ ) or a reported history of fever within the last 7 days were eligible. Children presenting without a parent or guardian to provide consent were excluded. After consent was provided, study personnel recorded demographic information, vital signs, and administered a brief health questionnaire (Supplementary Annex 1).

Laboratory staff performed a malaria rapid diagnostic test (mRDT) (SD Bioline Malaria Ag P.f, Standard Diagnostics, Republic of Korea) and collected dried blood spots (DBS) on filter paper (Whatman, Chicago, IL). DBS sampling was chosen as a pragmatic but effective option for sampling children across the different field conditions at our study sites [15]. The reliability of measuring antibodies eluted from DBS has been validated several times, $[16,17]$ and we and others have used DBS-based serology to study the epidemiology of arboviruses in both standard ELISA as well as multiplex platforms [18-20]. Children with a positive mRDT result were excluded from further participation. Children with a negative mRDT result subsequently underwent testing with a dengue rapid diagnostic test (dRDT) (SD Bioline Dengue Duo, Standard Diagnostics Korea). Using excess dRDTs, we also tested a subset of participants with a positive mRDT to explore the possibility of dengue-malaria co-infection. Participants at the Mbarara site located at the Mbarara Regional Referral Hospital outpatient clinic, where reliable sample processing and storage facilities were available, had $5 \mathrm{~mL}$ of venous rather than capillary blood drawn into serum serparator tubes for further testing in addition to the dRDT.

Results of the dRDT were provided to the responsible clinician for the purposes of counseling and case management. Treatment and disposition (i.e. admission versus discharge) plans, as determined by the clinician, were recorded. DBS were stored at room temperature under desiccation and serum samples were stored at $20^{\circ} \mathrm{C}$ until analysis.

\section{Laboratory methods}

All RDTs for the study were obtained directly from the manufacturer, stored in the original packaging at room temperature, and used in accordance with the manufacturer's instructions prior to the expiration date. In brief, whole blood, either capillary (i.e. via finger prick) or venous was applied directly into the specimen wells of the malaria and/or dengue RDT. 

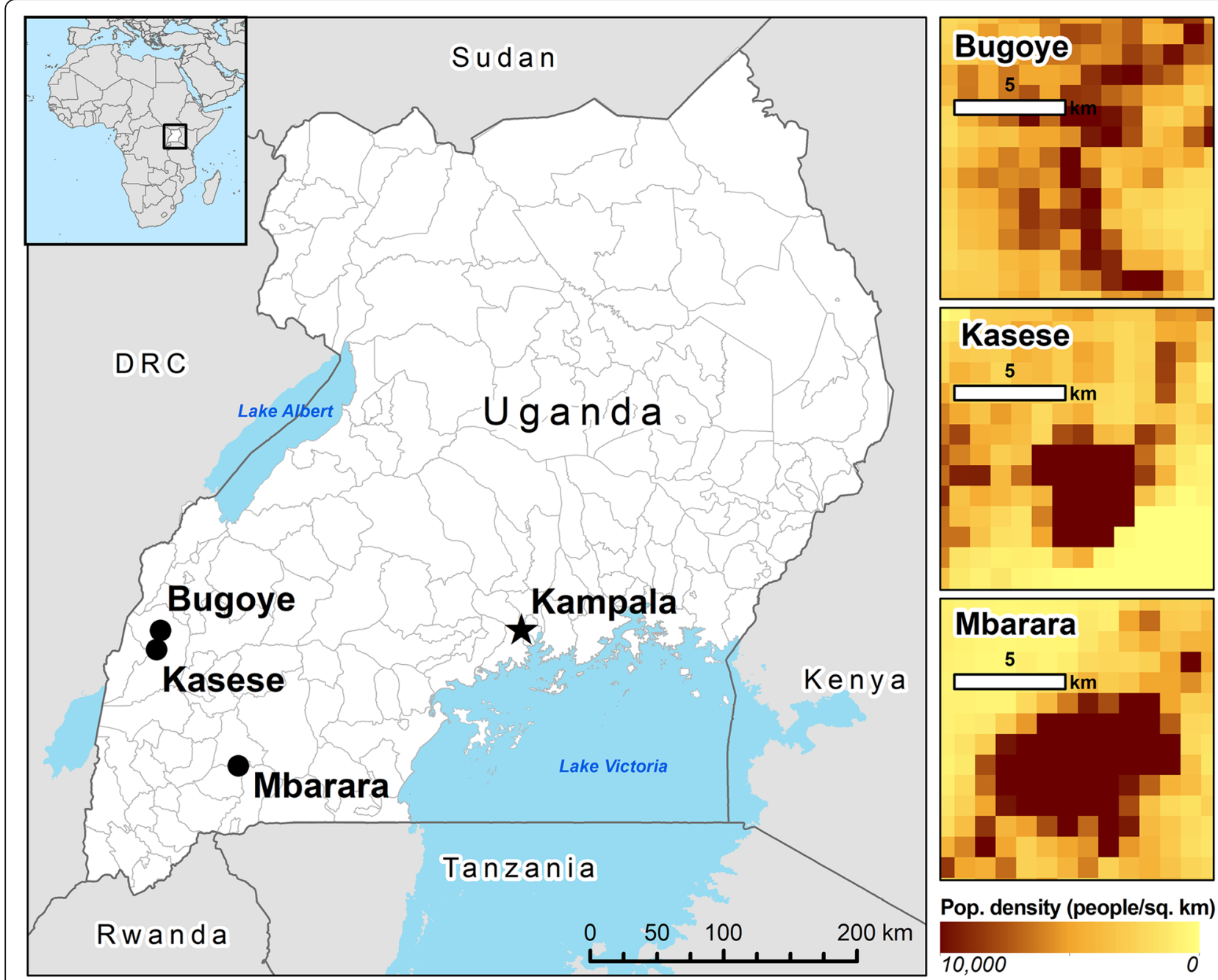

Fig. 1 Map showing location of study sites and population density of each location

Assay diluent was added into the round well of the malaria and dengue $\operatorname{IgM} / \operatorname{IgG}$ cassettes and the test was allowed to run for $15-20 \mathrm{~min}$. Two staff members recorded the RDT results. A third, senior staff member adjudicated any discrepancies between the initial reads.

Further description of specific procedures is provided below.
Elution of dried blood spots for serologic analysis

Plasma proteins were eluted from DBS as previously described [18-20]. One 6-mm hole punch of each DBS was placed in a $1.5 \mathrm{~mL}$ Eppendorf tube with $300 \mu \mathrm{L}$ of phosphate-buffered saline, and rotated for $2 \mathrm{~h}$ at $37^{\circ} \mathrm{C}$. This yielded an eluate that is equivalent to a 1:40 plasma dilution. Eppendorf tubes were centrifuged then eluate transferred to a new tube. Eluate was heat inactivated

Table 1 Description of clinical sites

\begin{tabular}{|c|c|c|c|c|c|c|c|c|c|}
\hline Study Site & Location & District & GPS & Elevation & Setting & Facility Type & $\begin{array}{l}\text { Referral } \\
\text { Base }\end{array}$ & $\begin{array}{l}\text { Monthly } \\
\text { Clinic } \\
\text { Visits }\end{array}$ & $\begin{array}{l}\text { Malaria } \\
\text { Prevalence }^{a}\end{array}$ \\
\hline Bugoye Health Centre III & $\begin{array}{l}\text { Bugoye } \\
\text { Village }\end{array}$ & Kasese & $\begin{array}{l}0.3019 \\
30.0984\end{array}$ & $1242 m$ & Rural & $\begin{array}{l}\text { Public Health } \\
\text { Centre III }\end{array}$ & 50,000 & 800 & $17.6 \%$ \\
\hline Kasese Health Centre III & $\begin{array}{l}\text { Kasese } \\
\text { Town }\end{array}$ & Kasese & $\begin{array}{l}0.1806 \\
30.0782\end{array}$ & 980 m & $\begin{array}{l}\text { Semi- } \\
\text { Urban }\end{array}$ & $\begin{array}{l}\text { Public Health } \\
\text { Center III }\end{array}$ & 400,000 & 1200 & $17.6 \%$ \\
\hline $\begin{array}{l}\text { Mbarara Regional Referral } \\
\text { Hospital }\end{array}$ & $\begin{array}{l}\text { Mbarara } \\
\text { Town }\end{array}$ & Mbarara & $\begin{array}{l}-0.6178 \\
30.6586\end{array}$ & $1442 \mathrm{~m}$ & Urban & $\begin{array}{l}\text { Public Teaching } \\
\text { Hospital }\end{array}$ & 2.5 million & 1600 & $5.7 \%$ \\
\hline
\end{tabular}

${ }^{a}$ Regional estimates from 2014 to 15 Uganda Malaria Indicator Survey [12] 
for $30 \mathrm{~min}$ in a $56^{\circ} \mathrm{C}$ water bath. The samples were centrifuged again to pellet proteinaceous debris and the supernatant was transferred to a new tube and stored at $4{ }^{\circ} \mathrm{C}$ for up to 1 week or at $-20^{\circ} \mathrm{C}$ until use.

\section{Antigen capture IgG ELISA}

Binding IgG to DENV or ZIKV was measured by antigen capture ELISA as previously described [21]. Briefly, DENV antigen (an equal volume mixture of supernatant from each of the four DENV serotypes cultured in C6/ 36 cells) was captured by the anti-E protein mouse mAb 4G2 [22]. Plates were blocked with $3 \%$ nonfat dry milk, and incubated with DBS eluate at $37^{\circ} \mathrm{C}$ for $1 \mathrm{~h}$, and binding was detected with an alkaline phosphataseconjugated goat anti-human IgG secondary Ab and $p$-nitrophenyl phosphate substrate. Absorbance at $405 \mathrm{~nm}$ (optical density, OD) was measured by spectrophotometry on a plate reader. ELISA data are reported as OD values that are the average of technical replicates. The average OD for technical replicates using DBS eluate obtained from flavivirus-naïve individuals (NHS) served as the negative control in ELISA assays. The cut off for positivity was calculated for each plate as the average OD of NHS = standard deviations + 0.1 [18-20].

\section{IgM ELISA}

Testing for anti-DENV IgM was only performed on participant samples with either a positive dRDT or IgG ELISA per CDC MAC ELISA protocol after titrating individual reagents per instructions [23]. DBS eluate was tested at 1:40 dilution. DENV1-4 antigen was the same as for IgG ELISA above. Plates were washed 3 times between each step. The Enhanced K-Blue TMB substrate reaction was stopped after $30 \mathrm{~min}$ by addition of $50 \mu \mathrm{L} 1$ $\mathrm{N} \mathrm{HCl}$. Optical density (OD) of each well was determined within $5 \mathrm{~min}$ at $450 \mathrm{~nm}$.

\section{Neutralization assays}

Neutralization titers were determined by 96-well microFRNT $[24,25]$. Due to limited sample availability from DBS, an abbreviated neutralization assay format was used (eFRNT). DBS eluates were run in singleton over four 4-fold dilutions. Serial dilutions of DBS eluate were mixed with approximately $75-100$ focus-forming units of virus in DMEM with $2 \%$ FBS. The virusantibody mixtures were incubated for $1 \mathrm{~h}$ at $37^{\circ} \mathrm{C}$ and then transferred to a monolayer of Vero cells for infection for $2 \mathrm{~h}$ at $37^{\circ} \mathrm{C}$. OptiMEM overlay media supplemented with $2 \%$ FBS and $5 \mathrm{~g}(1 \%)$ Carboxymethylcellulose was then added, and cultures were incubated for $48 \mathrm{~h}$ (DENV2 and DENV4) or $52 \mathrm{~h}$ (DENV1, DENV3). Cells were fixed with $100 \mu \mathrm{L}$ of 1:1 methanol:acetone for $30 \mathrm{~min}$. $100 \mu \mathrm{L}$ of permeabilization buffer was added for $10 \mathrm{~min}$ followed by $100 \mu \mathrm{L}$ of blocking buffer (3\% normal goat plasma in permeabilization buffer) and left overnight at $4{ }^{\circ} \mathrm{C} .50 \mu \mathrm{L}$ of $4 \mathrm{G} 2$ at $12.5 \mathrm{ng} / \mu \mathrm{L}$ were added to the plates and incubated for $1 \mathrm{~h}$ at $37^{\circ} \mathrm{C}$. Cells were washed with a microplate washer followed by the addition of $50 \mu \mathrm{l}$ of 1:3000 horseradish peroxidaseconjugated goat anti-mouse secondary antibody for $1 \mathrm{~h}$ at $37^{\circ} \mathrm{C}$. Foci were visualized with $100 \mu \mathrm{L}$ of True Blue and counted with a user-supervised automated counting program on 2x-magnified images of micro-wells obtained on a CTL ELISPOT reader. NHS controls were included on every plate to define $100 \%$ infection. The eFRNT value is a discrete number corresponding to the dilution factor at which 50\% maximum FFU are observed or the average of the two dilution factors between which $50 \%$ FFU is crossed.

\section{Real-time polymerase chain reaction}

Whole blood was drawn into serum serparator tubes and centrifuged. Viral RNA was extracted from $140 \mu \mathrm{L}$ of serum using the QIAamp extraction kit (QIAGEN Hilden, Germany) and eluted in $60 \mu \mathrm{L}$. Real time PCR was performed on the Rotor-Gene Q (QIAGEN Hilden, Germany) platform using the RealStar kits for Dengue, V2.0, Chikungunya, V2.0 and Zika V.1.0 (Altona Diganostics, Hamburg, Germany) in accordance with manufacturer's instructions.

\section{Statistical analysis}

Data was collected in a REDCap database and analyzed with Stata 15.1 (College Station, TX) [26]. We summarized participant characteristics and compared them between those with positive and negative mRDT resuts using Student's t-test (normally distributed data) or Wilcoxon rank-sum test (nonparametric data) for continuous variables and Pearson $\mathrm{x} 2$ test for categorical variables. We determined the incidence rate ratio (IRR) of malaria among individuals with self-reported bed net use as the primary explanatory variable using generalized negative binomial regression models with robust standard errors. In a post-hoc analysis, we performed multivariable regression analyses to explore the demographic, geographic, and clinical parameters associated with the primary outcome of interest: a positive dengue IgG. All variables that were significant in univariate models with a pre-specified $p$-value of $<0.25$ were included in the subsequent multivariate analysis [27]. A resulting $p$-value of $<0.05$ was considered statistically significant in the final models.

\section{Results}

A total of 1702 children met the eligibility criteria and were screened for malaria with a mRDT. Complete laboratory results were available for 1693 (99.5\%) particpants, who were subsequently included in the analysis. 
Characteristics of the cohort are summarized in Table 2. The median age was 5 years (IQR 2-10), although children at Bugoye were significantly older (10 years, IQR $5-14, p<0.0001)$, likely attributable to an existing village-based, community health worker led fever management intervention targeting children less than 5 years of age and reducing the number of these patients that presented to our study site [28].

Overall, 369 children $(21.8 \%)$ had a positive mRDT result. The lowest rate was observed at MRRH (17 of 455, 3.7, 95\% CI 2.3-5.9), whereas much higher rates were seen in Kasese (138 of 606, 22.8, 95\% CI 19.6-26.3) and Bugoye (214 of 632, 33.9, 95\% CI 30.3-37.7). Selfreported ITN use was associated with a protective effect against malaria (IRR 0.70, 95\% CI 0.54-0.90, $p=0.006$ ), but when the analysis was limited only to the hightransmission areas with higher risk, the protective effect was no longer significant (IRR 0.85, 95\% CI 0.65-1.11, $p=0.25)$.

There was overlap in self-reported symptoms between children with positive and negative mRDT results (Table 2). Among all participants, cough (69.1\%), headache $(63.6 \%)$, and rhinorrhea (53.0\%) were the most frequently reported symptoms. A total of $431(25.4 \%)$ participants reported all three of these symptoms, 364 (84.5\%) of whom had a negative mRDT result. Participants with a negative mRDT were also more likely to have sought care and received treatment for malaria

Table 2 Demographic and clinical characteristics of the study cohort

\begin{tabular}{|c|c|c|c|c|}
\hline Characteristic & All & Malaria RDT Positive & Malaria RDT Negative & $p$-Value \\
\hline Patients (n, \%) & $1693(100)$ & $369(21.8)$ & $1324(78.2)$ & - \\
\hline Age, (median, IQR) & $5(2-10)$ & $7(4-11)$ & $4(2-9)$ & $<0.001^{*}$ \\
\hline$<5$ years & $788(46.5)$ & $122(33.1)$ & $666(50.3)$ & \\
\hline $5-12$ years & $577(34.1)$ & $155(42.0)$ & $422(31.9)$ & $<0.001$ \\
\hline$\geq 12$ years & $328(19.4)$ & $92(24.9)$ & $236(17.8)$ & \\
\hline Female sex $(n, \%)$ & $904(53.4)$ & $200(54.2)$ & $704(53.2)$ & 0.73 \\
\hline \multicolumn{5}{|l|}{ Recruitment Site $(n, \%)$} \\
\hline Bugoye & $632(37.3)$ & $214(58.0)$ & 418 (31.6) & \\
\hline Kasese & $606(35.8)$ & $138(37.4)$ & $468(35.4)$ & $<0.001$ \\
\hline Mbarara & $455(26.9)$ & $17(4.6)$ & $438(33.1)$ & \\
\hline Slept under bednet $(n, \%)$ & $1222(73.0)$ & $244(67.2)$ & $978(74.5)$ & 0.005 \\
\hline Excluding Mbarara & $858(70.3)$ & $235(67.9)$ & $623(71.3)$ & 0.25 \\
\hline $\begin{array}{l}\text { Days since fever onset } \\
\text { (median, IQR)* }^{*}\end{array}$ & $3(2-3)$ & $3(2-3)$ & $3(2-3)$ & $0.0008^{*}$ \\
\hline \multicolumn{5}{|l|}{ Reported Symptoms } \\
\hline Anorexia/Poor Feeding & $234(13.8)$ & $56(15.2)$ & $178(13.4)$ & 0.39 \\
\hline Arthralgia & $170(10.0)$ & $64(17.3)$ & $106(8.0)$ & $<0.001$ \\
\hline Cough & $1178(69.1)$ & $208(56.1)$ & $970(72.7)$ & $<0.001$ \\
\hline Diarrhea & $234(13.8)$ & $34(9.2)$ & $200(15.1)$ & 0.004 \\
\hline Headache & $1076(63.6)$ & $276(74.8)$ & $800(60.4)$ & $<0.001$ \\
\hline Myalgia & $143(8.5)$ & $59(16.0)$ & $84(6.3)$ & $<0.001$ \\
\hline Rash & $92(5.4 \%)$ & $15(4.1)$ & $77(5.8)$ & 0.19 \\
\hline Rhinorrhea & $897(53.0)$ & $134(36.3)$ & $763(57.6)$ & $<0.001$ \\
\hline Seizures & $6(0.4)$ & $1(0.3)$ & $5(0.4)$ & 0.76 \\
\hline Vomiting & $248(14.7)$ & $46(12.5)$ & $202(15.3)$ & 0.18 \\
\hline \multicolumn{5}{|l|}{ Abnormal Vital Signs (n, \%) } \\
\hline Febrile $\left(T \geq 38^{\circ} \mathrm{C}\right)$ & $281(16.6)$ & $75(20.3)$ & $206(15.6)$ & 0.03 \\
\hline Hypoxia (SpO2<90\%) & $93(5.5)$ & $12(3.3)$ & $81(6.2)$ & 0.03 \\
\hline Previously seen at health center for same condition? & $252(15.0)$ & $30(8.2)$ & $222(16.8)$ & $<0.001$ \\
\hline Taken antimalarials in the last 2 weeks? & $175(10.4)$ & $26(7.1)$ & $149(11.3)$ & 0.02 \\
\hline
\end{tabular}


within the past 14 days. In contrast, arthralgia and myalgia were more frequently reported in the mRDT positive group.

Of the 1324 participants with a negative mRDT test result, 1285 (97.1\%) had an evaluable dRDT result, of which $5(0.39 \%)$ had a positive result, defined as a visible NS1, IgM, or IgG band. Individual tests results include one child with positive IgM bands, three with positive IgG bands, and one with positive IgM and IgG bands. There were three positive dRDT results in Bugoye, two in Mbarara, and and one in Kasese (Fig. 2) All 414 samples from MRRH tested by RT-PCR were negative for DENV, CHIKV, and ZIKV.

Serological testing of 1247 (94.2\%) DBS samples from participants with a negative mRDT test result identified reactive IgG antibodies in $28(2.3 \%)$ participants. Demographic and clinical characteristics are summarized in Table 3. There was a significant difference in seroprevalence between Mbarara (19 of 392, 4.9\%), which is a more urban center, and the rural sites (Kasese 2 of 453, $0.4 \%$; Bugoye 7 of 414, 1.7\%; $p<0.001$ ). The Mbarara study site was the only significant predictor of a dengue infection in the multivariable analysis when using Kasese as the reference, although there was a statistical trend towards males being at higher risk of infection $(p=0.10)$ (Table 4). Samples that were positive by RDT or IgG ELISA were also tested by eFRNT and DENV IgMELISA, but none were positive for IgM antibodies.
Of the 28 participants with a reactive IgG antibodies by ELISA, only $1(3.6 \%)$ had a positive IgG band on the dRDT. This occurred in the one patient with both IgM and IgG bands positive on the dRDT. Overall, the correlation in IgG results between the dRDT and ELISA was poor $(\kappa=0.06,95 \%$ CI $0-0.40)$.

Among those with a negative mRDT result, 1297 of 1324 (98.0\%) received treatment with an antibiotic, including five who also received treatment with artemether/lumefantrine (AL). An additional 17 (1.3\%) received treatment with $\mathrm{AL}$ (and no antibiotic) despite negative mRDT test results. There were no differences in the rate of antibiotic administration between children with a reactive $\operatorname{IgG}$ antibody result and those without (96.4\% vs. $97.48 \%, p=0.73$ ). The vast majority of children (1279 of 1316, 97.2\%) were discharged from the outpatient clinics, while 35 (2.7\%) were admitted. Children with a anti-dengue IgG were admitted from the outpatient clinic at a higher rate, although the absolute number of admissions was low $(3,11.1 \%$ vs. $26,2.3 \%$, $p=0.01$ ). There were no significant differences in admission rates by sex, age category, or clinical site.

\section{Discussion}

Despite favorable climate and ecology, our findings suggest that dengue is an uncommon cause of non-malarial, pediatric febrile illness in western Uganda. Our results are consistent with those obtained from a laboratory-

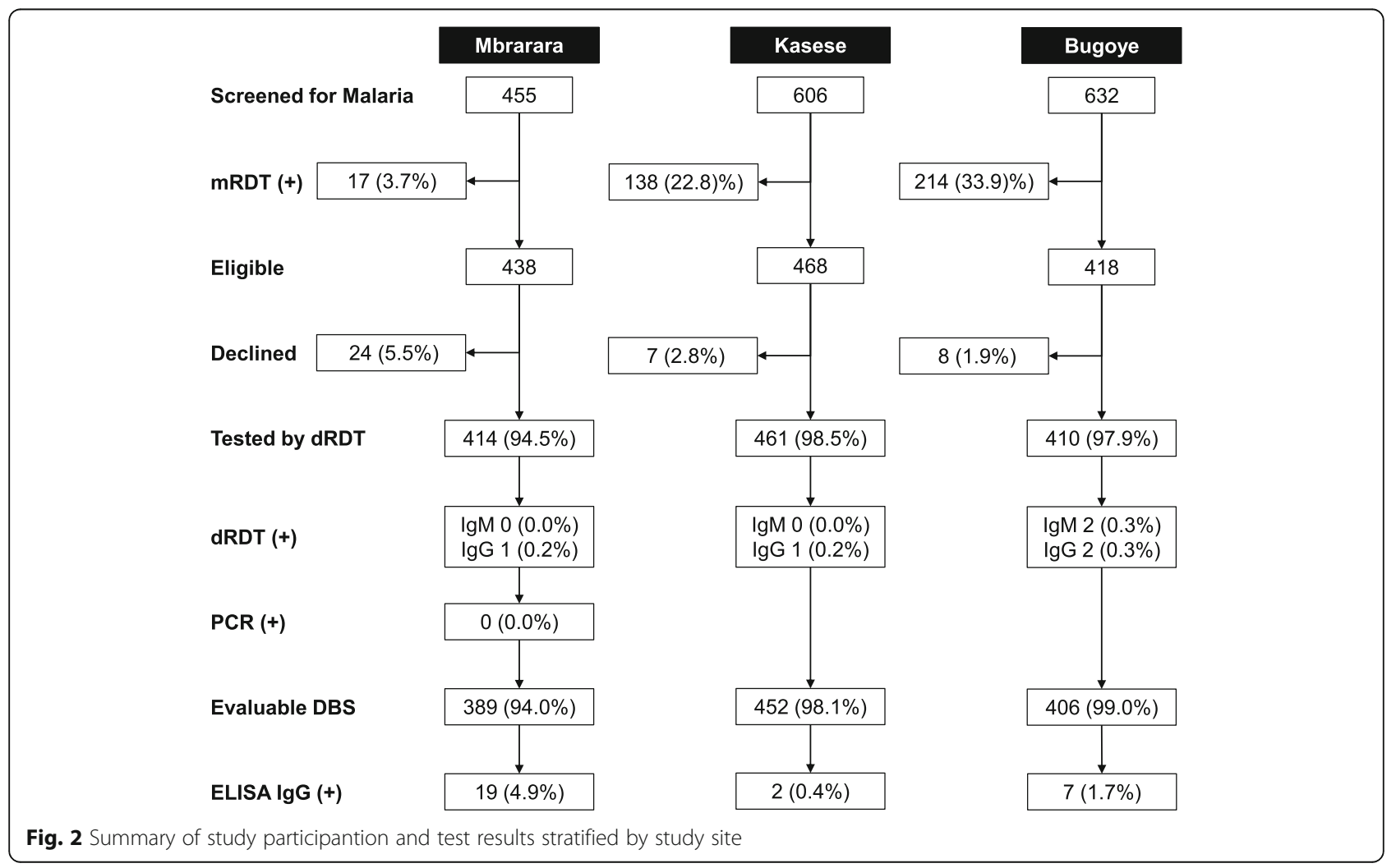


Table 3 Demographic and clinical characteristics of participants stratified by Dengue IgG result

\begin{tabular}{|c|c|c|c|}
\hline Characteristic & Dengue IgG Negative & Dengue IgG Positive & $p$-Value \\
\hline Patients (n, \%) & $1219(97.8)$ & $28(2.3)$ & - \\
\hline Age, (median, IQR) & $5(2-10)$ & $5(2-9)$ & 0.76 \\
\hline$<5$ years & 605 (49.6) & $12(42.9)$ & \\
\hline $5-12$ years & 387 (31.8) & $11(39.3)$ & 0.69 \\
\hline$\geq 12$ years & 227 18.6) & $5(17.9)$ & \\
\hline Female sex $(n, \%)$ & $654(53.7)$ & $10(35.7)$ & 0.06 \\
\hline \multicolumn{4}{|l|}{ Recruitment Site $(n, \%)$} \\
\hline Bugoye & $399(32.7)$ & $7(25.0)$ & \\
\hline Kasese & $450(36.9)$ & $2(7.1)$ & $<0.001$ \\
\hline Mbarara & $370(30.4)$ & $19(67.9)$ & \\
\hline Slept under bednet $(n, \%)$ & $895(94.1)$ & $23(82.1)$ & 0.34 \\
\hline $\begin{array}{l}\text { Days since fever onset } \\
\text { (median, IQR) }^{*}\end{array}$ & $3(2-3)$ & $3(2-5.5)$ & $0.002^{*}$ \\
\hline \multicolumn{4}{|l|}{ Reported Symptoms } \\
\hline Anorexia/Poor Feeding & 159 (13.0) & $5(17.9)$ & 0.46 \\
\hline Arthralgia & $100(8.2)$ & $2(7.1)$ & 0.84 \\
\hline Cough & $883(72.4)$ & $19(67.9)$ & 0.59 \\
\hline Diarrhea & $170(14.0)$ & $8(28.6)$ & 0.03 \\
\hline Headache & $744(61.0)$ & $16(57.1)$ & 0.68 \\
\hline Myalgia & $80(6.6)$ & $1(6.3)$ & 0.53 \\
\hline Rash & $71(5.8)$ & $4(14.3)$ & 0.06 \\
\hline Rhinorrhea & $696(57.1)$ & $13(46.4)$ & 0.26 \\
\hline Seizures & $4(0.3)$ & $0(0.0)$ & 0.76 \\
\hline Vomiting & $177(14.5)$ & $7(25.0)$ & 0.12 \\
\hline \multicolumn{4}{|l|}{ Abnormal Vital Signs (n, \%) } \\
\hline Febrile $\left(T \geq 38^{\circ} \mathrm{C}\right)$ & $189(15.5)$ & $2(7.1)$ & 0.22 \\
\hline Hypoxia (SpO2 < 90\%) & $76(6.3)$ & $3(10.7)$ & 0.34 \\
\hline Previously seen at health center for same condition? & $190(15.7)$ & $9(32.1)$ & 0.02 \\
\hline Taken antimalarials in the last 2 weeks? & $126(10.4)$ & $6(22.2)$ & 0.05 \\
\hline
\end{tabular}

Abbreviations: RDT Rapid diagnostic test, IQR Interquartile range, $C^{\circ}$ Degrees celsisus, Spo2 Oxygen saturation as measured by pulse oximeter. *Determined using Wilcoxon Rank Sum

based surveillance system of inpatient pediatric admissions across six sentinel sites in Uganda, which reported recent arboviral infection in only 18 of $622(2.9 \%)$ samples tested [29], as well as multi-site seroprevalence study of healthy adult blood donors, which identified dengue antibodies in 72 of 1744 (4.1\%) of donors [30]. However, these data exclude neither the possibility of sporadic dengue outbreaks in the past or future nor the possibility that dengue or other Aedes-borne viruses could establish endemicity in this region given the favorable ecological conditions. Our time-limited and geographically-restricted study design, however, does provide a robust snapshot of current arbovirus transmission. While seroprevalence studies that include older subjects may increase the sensivtivity for detecting historic dengue transmission, our findings do provide strong evidence for the presence of low-level transmission, particularly at the more urban site in Mbarara. In areas of higher transmission, dengue seroprevalence is typically $20 \%$ or greater in young children [31-33]. The few cases detected here, along with the large susceptible population make dengue introduction a major concern, and surveillance together with further investigation of the demographic, spatial, and entomologic factors that could support epidemic and endemic dengue infection in urban East Africa should be a high priority.

Given the low number of positive cases, a rigorous assessment of the performance of the dengue rapid diagnostic tests was not possible. The relatively poor correlation in IgG results between the dRDT and the 
Table 4 Regression modeling of variables associated with presence of dengue lgG

\begin{tabular}{|c|c|c|c|c|c|c|}
\hline \multirow[t]{2}{*}{ Variable } & \multicolumn{3}{|c|}{ Unadjusted } & \multicolumn{3}{|c|}{ Adjusted* } \\
\hline & OR & $95 \% \mathrm{Cl}$ & $p$-value & $\mathrm{aOR}$ & $95 \% \mathrm{Cl}$ & $p$-value \\
\hline Male sex & 2.08 & $0.95-4.54$ & 0.07 & 1.93 & $0.88-4.25$ & 0.10 \\
\hline \multicolumn{7}{|l|}{ Age category } \\
\hline$<5$ years & & REF & & & & \\
\hline $5-12$ years & 1.42 & $0.62-3.25$ & 0.41 & & & \\
\hline$\geq 12$ years & 1.10 & $0.39-3.16$ & 0.86 & & & \\
\hline \multicolumn{7}{|l|}{ Study site } \\
\hline Kasese & & REF & & & REF & \\
\hline Bugoye & 3.88 & $0.80-18.8$ & 0.09 & 4.08 & $0.84-19.8$ & 0.08 \\
\hline Mbarara & 11.5 & $2.66-49.6$ & 0.001 & 11.2 & $2.59-48.5$ & 0.001 \\
\hline Bednet use & 1.61 & $0.61-4.27$ & 0.34 & & & \\
\hline
\end{tabular}

* Variables that were significant in univariate models with a pre-specified $P$ value of $<0.25$ were included in the subsequent multivariate analysis

ELISA is consistent with a study of febrile outpatients conducted in the Democratic Republic of Congo, which showed $2.5 \%$ IgG positivity by $\mathrm{dRDT}$ and $34.0 \%$ positivity by ELISA with an estimated sensitivity of 7.6\% [34]. It is crucial to note that dRDT are designed for use in the setting of acute infection and not for seroprevalence studies. The main advantage of including IgG testing in this context is in secondary infection, when IgG may rise quickly and dramatically, suppressing the IgM response and limiting unbound dengue antigen present in serum [35]. In primary infection, patients would typically present before an IgG response has developed. A recent systematic review evaluated the potential of dRDT to function as a measure of seroprevalence but found performance to be suboptimal, with sensitivity ranging from 30 to $60 \%$ [36].

Our results do highlight the urgent need for better diagnostics and management algorithms for children with acute febrile illness. Malaria was identified as the cause of fever in only $22 \%$ of participants, and among participants with a negative malaria test, nearly $80 \%$ reported cough or rhinorrhea with more than half (51.1\%) reporting both symptoms. While not confirmed by microbiologic or molecular methods, many of these children likely had viral infections, including other arboviral diseases such as West Nile or Chikungunya [30], that would be self-limited and not require antibiotic treatment [37]. Yet more than $97 \%$ of children with a negative malaria test result across all three sites received a course of antibiotic treatment. Given the growing global threat of antimicrobial resistance, driven in part by antimicrobial overuse, this patient population represents an important target for antibiotic stewardship interventions.

To our knowledge, our study is one of the first to examine the burden of dengue among children presenting to outpatient clinics in western Uganda with undifferentiated febrile illness. Strengths of our approach include the diverse geography of the clinical sites, large sample size, and different diagnostic testing strategies (i.e. dRDT, ELISA, PCR). The study also has a number of limitations. First, we excluded children with a positive mRDT from further consideration. While denguemalaria coinfections have been reported in other countries [7, 38, 39], this was expected to be a relatively infrequent occurrence. To explore this possibility, however, we tested 131 mRDT positive children at the Kasese site, only one $(0.77 \%)$ of who had a positive IgM band on the dRDT; a prevalence similar to children with a negative $\operatorname{mRDT}(p=0.53)$. Second, our facility-based and temporally-limited enrollment strategy may have missed focal outbreaks of dengue in the community. Dengue is well-known to emerge rapidly in non-immune populations then quickly disappear. Studies from neighboring countries and other surveillance methods do, however, support the validity of our findings. Third, we did experience some attrition of samples, due to improper labeling, inadequate specimen, or loss/damage in transport. We were, however, able to complete dRDT and ELISA testing in more than 97 and $94 \%$ of eligible participants, respectively. Fourth, IgG ELISA may overestimate dengue prevalence as this assay may also detect cross-reactive antibodies elicited by infection by related flaviviruses, though neutralization testing also supported prior infection by dengue for some subjects in this population [40, 41]. Lastly, we did not have the means to screen all specimens for anti-dengue $\operatorname{IgM}$, which precluded a direct comparison of serologic IgM testing to the dRDT result.

\section{Conclusions}

Dengue does not account for a large proportion of nonmalarial, acute febrile illness presentations in western Uganda. However, the presence of the vector and the pathogen, along with a large susceptible population make sporadic outbreaks a major concern. Further investigation into the ecological factors that sustain lowlevel transmission in urban centers such as our Mbarara site, are urgently needed.

\section{Supplementary Information}

The online version contains supplementary material available at https://doi. org/10.1186/s12879-020-05568-5.

\section{Additional file 1.}

\section{Abbreviations}

ACT: Artemisinin combination therapies; AL: Artemether/lumefantrine; $\mathrm{C}^{\circ}$ : Degrees Celsius; CHIKV: Chikungunya Virus; DBS: Dried Blood Spot; DENV: Dengue Virus; dRDT: Dengue rapid diagnostic test; ELISA: Enzyme Linked immunosorbent Assay; ITN: Insecticide-treated nets; mRDT: Malaria 
rapid diagnostic test; MRRH: Mbarara Regional Referral Hospital; NS1: Nonstructural protein 1; OD: Optical Density; RNA: Ribonucleic acid; RTPCR: Reverse-Transcriptase Polymerase Chain Reaction; ZIKV: Zika Virus

\section{Acknowledgements}

We wish to thank the clinical staff and patients of the Bugoye Health Centre, Kasese Health Centre, and Mbarara Regional Referral Hospital Outpatient Department for their participation and support. We also thank Corinna Keeler for the cartography support.

\section{Authors' contributions}

Study conception and design: RMB, MHC, EM. Funding: RMB. Study implementation: RMB, RM, RN, EC MM, MN, DN, EM. Laboratory testing: RN, DN, SG, DE, YZ, MHC, JJJ. First draft of manuscript: RMB, SG, EC, MHC, DN. Revisions: All. The author(s) read and approved the final manuscript.

\section{Funding}

The study was supported by Takeda Vaccines. Standard Diagnostics provided the rapid diagnostic tests for the study at no cost. RMB is supported by the National Institutes of Health (K23Al141764). JJJ received support from National Institute of Health (K24Al13499). EJC is supported by the National Institutes of Health (5T32HL007106-43). Neither Takeda nor Standard Diagnostics nor had any role in the design or conduct of the study or preparation of the manuscript.

\section{Availability of data and materials}

Deidentified individual data that supports the results will be shared beginning 9 to 36 months following publication provided the investigator who proposes to use the data has approval from an Institutional Review Board (IRB), Independent Ethics Committee (IEC), or Research Ethics Board (REB), as applicable, and executes a data use/sharing agreement with UNC.

\section{Ethics approval and consent to participate}

Ethical approval of the study was provided by the institutional review boards of the University of North Carolina at Chapel Hill (16-2128), the Mbarara University of Science and Technology (01/03-16), and the Uganda National Council for Science and Technology (HS 2115). Written informed consent for participation in the study was obtained from all adult participants or from their parent or guardian when participants were children (under 18 years old).

\section{Consent for publication}

Not applicable.

\section{Competing interests}

All authors have completed the ICMJE uniform disclosure form and declare: no financial relationships with any organisations that might have an interest in the submitted work in the previous 3 years; no other relationships or activities that could appear to have influenced the submitted work.

\section{Author details}

'Division of Infectious Diseases, University of North Carolina at Chapel Hill, Chapel Hill, North Carolina 27599, USA. 'Department of Community Health, Faculty of Medicine, Mbarara University of Science \& Technology, Mbarara, Uganda. ${ }^{3}$ Division of Infectious Diseases, Emory University, Atlanta, GA 30322, USA. ${ }^{4}$ College of Arts and Sciences, University of North Carolina at Chape Hill, Chapel Hill, North Carolina 27599, USA. ${ }^{5}$ Epicentre Mbarara Research Centre, Mbarara, Uganda.

\section{Received: 27 July 2020 Accepted: 30 October 2020}

\section{Published online: 11 November 2020}

\section{References}

1. Bhatt $\mathrm{S}$, Gething PW, Brady OJ, Messina JP, Farlow AW, Moyes CL, Drake JM, Brownstein JS, Hoen AG, Sankoh O, et al. The global distribution and burden of dengue. Nature. 2013;496(7446):504-7.

2. Simmons CP, Farrar JJ, Nguyen W, Wills B. Dengue. N Engl J Med. 2012 366(15):1423-32.

3. Brady OJ, Gething PW, Bhatt S, Messina JP, Brownstein JS, Hoen AG, Moyes CL, Farlow AW, Scott TW, Hay SI. Refining the global spatial limits of dengue virus transmission by evidence-based consensus. PLoS Negl Trop Dis. 2012; 6(8):e1760.
4. WHO. WHO report on global surveillance of epidemic-prone infectious diseases: dengue and dengue haemorrhagic fever. Geneva: World Health Organization; 2014.

5. Simo FBN, Bigna JJ, Kenmoe S, Ndangang MS, Temfack E, Moundipa PF, Demanou M. Dengue virus infection in people residing in Africa: a systematic review and meta-analysis of prevalence studies. Sci Rep. 2019:9(1):13626.

6. Amarasinghe A, Kuritsk JN, Letson GW, Margolis HS. Dengue virus infection in Africa. Emerg Infect Dis. 2011;17(8):1349-54.

7. Chipwaza B, Mugasa JP, Selemani M, Amuri M, Mosha F, Ngatunga SD, Gwakisa PS. Dengue and Chikungunya fever among viral diseases in outpatient febrile children in Kilosa district hospital, Tanzania. PLoS Negl Trop Dis. 2014;8(11):e3335.

8. Jaenisch T, Junghanss T, Wills B, Brady OJ, Eckerle I, Farlow A, et al. Dengue expansion in Africa-not recognized or not happening? Emerg Infect Dis [Internet]. 2014. https://dx.doi.org/10.3201/eid2010.140487.

9. Statistics UBo. National Population and housing census 2014. Kampala: Republic of Uganda; 2014.

10. Anders $\mathrm{KL}$, Hay SI. Lessons from malaria control to help meet the rising challenge of dengue. Lancet Infect Dis. 2012;12(12):977-84.

11. Deng SQ, Yang X, Wei Y, Chen JT, Wang XJ, Peng HJ. A Review on Dengue Vaccine Development. Vaccines (Basel). 2020;8(1):63.

12. Uganda Bureau of Statistics. Uganda Malaria Indicator Survey 2014-15. Kampala, Uganda, and Rockville, Maryland, USA: International. Ual; 2015.

13. Yeka A, Gasasira A, Mpimbaza A, Achan J, Nankabirwa J, Nsobya S, Staedke SG, Donnelly MJ, Wabwire-Mangen F, Talisuna A, et al. Malaria in Uganda: challenges to control on the long road to elimination: I. epidemiology and current control efforts. Acta Trop. 2012;121(3):184-95.

14. Uganda Ministry of Health. National Guidelines for the Management of Common Conditions. Kampala, Uganda; 2016. http://library.health.go.ug/ publications/guidelines/uganda-clinical-guidelines-2016.

15. Lim MD. Dried blood spots for Global Health diagnostics and surveillance: opportunities and challenges. Am J Trop Med Hygiene. 2018;99(2):256-65.

16. Andersen NJ, Mondal TK, Preissler MT, Freed BM, Stockinger S, Bell E, Druschel C, Louis GM, Lawrence DA. Detection of immunoglobulin isotypes from dried blood spots. J Immunol Methods. 2014:404:24-32

17. Behets F, Kashamuka M, Pappaioanou M, Green TA, Ryder RW, Batter V, George JR, Hannon WH, Quinn TC. Stability of human immunodeficiency virus type 1 antibodies in whole blood dried on filter paper and stored under various tropical conditions in Kinshasa, Zaire. J Clin Microbiol. 1992; 30(5):1179-82.

18. Corbett KS, Katzelnick L, Tissera H, Amerasinghe A, de Silva AD, de Silva AM. Preexisting neutralizing antibody responses distinguish clinically inapparent and apparent dengue virus infections in a Sri Lankan pediatric cohort. J Infect Dis. 2015:211(4):590-9.

19. Tissera $H$, Amarasinghe $A$, De Silva AD, Kariyawasam $P$, Corbett $K S$, Katzelnick L, Tam C, Letson GW, Margolis HS, de Silva AM. Burden of dengue infection and disease in a pediatric cohort in urban Sri Lanka. Am J Trop Med Hygiene. 2014;91(1):132-7.

20. Willcox AC, Collins MH, Jadi R, Keeler C, Parr JB, Mumba D, Kashamuka M, Tshefu A, de Silva AM, Meshnick SR. Seroepidemiology of dengue, Zika, and yellow fever viruses among children in the Democratic Republic of the Congo. Am J Trop Med Hygiene. 2018:99(3):756-63.

21. de Alwis R, Smith SA, Olivarez NP, Messer WB, Huynh JP, Wahala WM, White U, Diamond MS, Baric RS, Crowe JE Jr, et al. Identification of human neutralizing antibodies that bind to complex epitopes on dengue virions. Proc Natl Acad Sci U S A. 2012:109(19):7439-44.

22. Henchal EA, Gentry MK, McCown JM, Brandt WE. Dengue virus-specific and flavivirus group determinants identified with monoclonal antibodies by indirect immunofluorescence. Am J Trop Med Hygiene. 1982;31(4):830-6.

23. Martin DA, Muth DA, Brown T, Johnson AJ, Karabatsos N, Roehrig JT. Standardization of immunoglobulin M capture enzyme-linked immunosorbent assays for routine diagnosis of arboviral infections. J Clin Microbiol. 2000:38(5):1823-6.

24. Collins MH, McGowan E, Jadi R, Young E, Lopez CA, Baric RS, Lazear HM, de Silva AM. Lack of durable cross-neutralizing antibodies against Zika virus from dengue virus infection. Emerg Infect Dis. 2017;23(5):773-81.

25. Swanstrom JA, Plante JA, Plante KS, Young EF, McGowan E, Gallichotte EN, Widman DG, Heise MT, de Silva AM, Baric RS. Dengue Virus Envelope Dimer Epitope Monoclonal Antibodies Isolated from Dengue Patients Are Protective against Zika Virus. mBio. 2016;7(4):e01123. 
26. Harris PA, Taylor R, Thielke R, Payne J, Gonzalez N, Conde JG. Research electronic data capture (REDCap)--a metadata-driven methodology and workflow process for providing translational research informatics support. J Biomed Inform. 2009:42(2):377-81.

27. Hosmer D, Lemeshow S. Applied logistic regression. New York: Wiley; 2000.

28. English L, Miller JS, Mbusa R, Matte M, Kenney J, Bwambale S, Ntaro M, Patel P, Mulogo E, Stone GS. Monitoring iCCM referral systems: Bugoye integrated community case management initiative (BIMI) in Uganda. Malar J. 2016;15:247.

29. Lamorde M, Mpimbaza A, Walwema R, Kamya M, Kapisi J, Kajumbula H, Sserwanga A, Namuganga JF, Kusemererwa A, Tasimwa H, et al. A crosscutting approach to surveillance and laboratory capacity as a platform to improve health security in Uganda. Health Secur. 2018;16(S1):S76-86.

30. Clements $T L$, Rossi CA, lrish AK, Kibuuka H, Eller LA, Robb ML, Kataaha P, Michael NL, Hensley LE, Schoepp RJ. Chikungunya and O'nyong-nyong Viruses in Uganda: Implications for Diagnostics. Open Forum Infect Dis. 2019;6(3):ofz001.

31. L'Azou M, Assoukpa J, Fanouillere K, Plennevaux E, Bonaparte M, Bouckenooghe A, Frago C, Noriega F, Zambrano B, Ochiai RL, et al. Dengue seroprevalence: data from the clinical development of a tetravalent dengue vaccine in 14 countries (2005-2014). Trans R Soc Trop Med Hyg. 2018;112(4): 158-68

32. Reller ME, de Silva AM, Miles JJ, Jadi RS, Broadwater A, Walker K, Woods C, Mayorga $\mathrm{O}$, Matute $\mathrm{A}$. Unsuspected dengue as a cause of acute febrile illness in children and adults in Western Nicaragua. PLoS Negl Trop Dis. 2016;10(10):e0005026.

33. Rojas DP, Barrera-Fuentes GA, Pavia-Ruz N, Salgado-Rodriguez M, CheMendoza A, Manrique-Saide P, Vazquez-Prokopec GM, Halloran ME, Longini IM, Gomez-Dantes H. Epidemiology of dengue and other arboviruses in a cohort of school children and their families in Yucatan, Mexico: baseline and first year follow-up. PLoS Negl Trop Dis. 2018;12(11):e0006847.

34. Proesmans S, Katshongo F, Milambu J, Fungula B, Muhindo Mavoko H, Ahuka-Mundeke S, Inocencio da Luz R, Van Esbroeck M, Arien KK, Cnops L, et al. Dengue and chikungunya among outpatients with acute undifferentiated fever in Kinshasa, Democratic Republic of Congo: a crosssectional study. PLoS Negl Trop Dis. 2019;13(9):e0007047.

35. Peeling RW, Artsob H, Pelegrino JL, Buchy P, Cardosa MJ, Devi S, Enria DA, Farrar J, Gubler DJ, Guzman MG, et al. Evaluation of diagnostic tests: dengue. Nat Rev Microbiol. 2010;8(12 Suppl):S30-8.

36. Luo R, Fongwen N, Kelly-Cirino C, Harris E, Wilder-Smith A, Peeling RW. Rapid diagnostic tests for determining dengue serostatus: a systematic review and key informant interviews. Clin Microbiol Infect. 2019;25(6): 659-66.

37. D'Acremont V, Kilowoko M, Kyungu E, Philipina S, Sangu W, Kahama-Maro J, Lengeler C, Cherpillod P, Kaiser L, Genton B. Beyond malaria--causes of fever in outpatient Tanzanian children. N Engl J Med. 2014;370(9):809-17.

38. Monamele GC, Demanou M. First documented evidence of dengue and malaria co-infection in children attending two health centers in Yaounde, Cameroon. Pan Afr Med J. 2018;29:227.

39. Mouiche MMM, Ntumvi NF, Maptue VT, Tamoufe U, Albert B, Ngum Ndze V Nwobegahay J, Gillis A, LeBreton M, Mclver DJ, et al. Evidence of low-level dengue virus circulation in the south region of Cameroon in 2018. Vector Borne Zoonotic Dis. 2020;20(4):314-7.

40. Allwinn R, Doerr HW, Emmerich P, Schmitz H, Preiser W. Cross-reactivity in flavivirus serology: new implications of an old finding? Med Microbiol Immunol. 2002;190(4):199-202.

41. Speer SD, Pierson TC. VIROLOGY. Diagnostics for Zika virus on the horizon. Science. 2016;353(6301):750-1.

\section{Publisher's Note}

Springer Nature remains neutral with regard to jurisdictional claims in published maps and institutional affiliations.

Ready to submit your research? Choose BMC and benefit from:

- fast, convenient online submission

- thorough peer review by experienced researchers in your field

- rapid publication on acceptance

- support for research data, including large and complex data types

- gold Open Access which fosters wider collaboration and increased citations

- maximum visibility for your research: over $100 \mathrm{M}$ website views per year

At BMC, research is always in progress.

Learn more biomedcentral.com/submissions 